\title{
Variations of the Superficial Peroneal Nerve and Its Terminal Branches in the Turkish Newborn Fetuses
}

\author{
Nervus Peroneus Superficialis ve Uç Dallarının Türkiye’de Bulunan \\ Yenidoğan Fetuslardaki Varyasyonları
}

\author{
Orhan BAS ${ }^{1}$, Sait BILGIC ${ }^{2}$, Ahmet SALBACAK ${ }^{3}$, Osman Fikret SONMEZ ${ }^{4}$, Adem ERKUT ${ }^{5}$ \\ ${ }^{1}$ Rize University, Faculty of Medicine, Department of Anatomy, Rize, Turkey \\ ${ }^{2}$ Ondokuz Mayis University, Faculty of Medicine, Department of Anatomy, Samsun, Turkey \\ ${ }^{3}$ Selcuk University, Meram Faculty of Medicine, Department of Anatomy, Konya, Turkey \\ ${ }^{4}$ Samsun Training and Research Hospital, Department of Neurosurgery, Samsun, Turkey \\ ${ }^{5}$ Rize University, Faculty of Medicine, Department of Orthopedics and Traumatology, Rize, Turkey
}

Correspondence address: Orhan BAS / E-mail: orhanbas55@hotmail.com

\begin{abstract}
AIM: The topography of the superficial peroneal nerve (SPN) and its terminal branches were studied, with the aim of providing further anatomical details for leg and foot in the Turkish newborn fetuses.

MATERIAL and METHODS: Limbs from twenty newborn cadavers were dissected. The course of the SPN on the leg and its terminal branches on the foot were investigated.

RESULTS: The SPN was lateral (75\%), anterior (15\%), or branched in both areas (10\%) of the cases. The SPN in the dorsum of the feet branched further into medial dorsal cutaneous nerve (MDCn) and intermediate dorsal cutaneous nerve (IDCn). In $82.5 \%$ of the cases the MDCn and the IDCn split into three and two branches, respectively. In $10 \%$ of the cases, the MDCn gave off three, and the IDCn one terminal branches. In $7.5 \%$ of the cases, the MDCn had three while the IDCn had two branches that communicated with the lateral dorsal cutaneous nerve.

CONCLUSION: The course of SPN on the anterolateral surface of the leg and its terminal branches on the dorsal surface of the foot were quite different. This unusual variant location will enable the surgeon to find and preserve the SPN and its terminal branches.

KEYWORDS: Common peroneal nerve, Superficial peroneal nerve, Medial dorsal cutaneous nerve, Intermediate dorsal cutaneous nerve, Cutaneous innervation
\end{abstract}

öz

AMAÇ: Nervus peroneus superficialis (SPN) ve uç dallarının ayak ve bacaktaki topografik anatomisi hakkında daha detaylı bilgi vermek amacıyla Türkiye'deki yenidoğan fetuslar üzerinde bu çalışma gerçekleştirildi.

YÖNTEM ve GEREÇ: Yirmi yenidoğan kadavrasında her iki alt ekstremite diseke edildi. SPN’nin bacağın anterolateral yüzündeki seyri ve uç dallarının ise ayağın dorsal yüzündeki seyri araştırıldı.

BULGULAR: Nervus peroneus superficialis'in, vakaların \%75'inde lateral, \%15'inde anterior ve \%10'unda ise iki dala ayrılıp her iki kompartmanda seyrettiği gözlendi. SPN ayağın dorsal yüzünde, nervus cutaneus dorsalis medialis (MDCn) ve nervus cutaneus dorsalis intermedialis (IDCn) dallarını veriyordu. Vakaların \%82,5'inde MDCn üç, IDCn ise iki uç dala ayrılıyordu. Vakaların \%10'unda ise MDCn üç, IDCn ise bir uç dala ayrılıyordu. Diğer \%7, $5^{\prime}$ lik vakada ise MDCn üç, IDCn iki dal veriyor ve IDCN nervus cutaneus dorsalis lateralis ile anastomoz yapıyordu.

SONUÇ: Nervus peroneus superficialis'in bacağın anterolateral yüzünde, uç dallarının ise ayağın dorsal yüzündeki seyri çok farklılk göstermektedir. Bu olağan dışı yerleşimlerin tanımlanması cerrahlara SPN ve uç dallarının korunmasında ve belirlenmesinde yardımcı olacaktır. ANAHTAR SÖZCÜKLER: Nervus peroneus communis, Nervus peroneus superficialis, Nervus cutaneus dorsalis medialis, nervus cutaneus dorsalis intermedialis, Deri innervasyonu

\section{INTRODUCTION}

The anatomy of the superficial peroneal nerve (SPN) is an important landmark in the leg for performing SPN neurolysis, compartment release, open reduction and internal fixation, as well as muscle flap procedures (11). The standard anatomic course of the SPN is to branch from the common peroneal nerve (CPN), which separates at the level of the neck of the fibula and passes laterally to the neck of the fibula $(15,22)$. Its course is at first deep in the peroneus longus muscle, passing antero-inferiorly between the peronei and extensor digitorum longus muscles $(7,8)$. The trunk of the nerve courses to the intermuscular septum between the lateral and anterior compartments $(17,21)$. The nerve pierces the superficial fascia and enters subcutaneous cellular tissue in the lower third of the leg $(4,13)$. The SPN of the leg comes down further to 
the foot, where it divides into terminal branches, the medial dorsal cutaneous nerve (MDCn) and the intermediate dorsal cutaneous nerve (IDCn) $(17,19)$.

Although this description of the nerve is considered to be the normal anatomy, the SPN may have different anatomical variations, which need to be taken under consideration by surgeons contemplating surgery on the SPN (5). This nerve is extremely vulnerable to injury (14), such as a direct blow, arthroscopy of the ankle, and surgical approaches to the lateral aspect of the ankle and hindfoot (10).

In order to better understand the anatomy of this nerve in detail, we examined the morphometric and topographic characteristics of the SPN, from its emergence to its branching and distribution in the skin on the anterolateral aspect of the leg and the dorsal aspect of the foot in the Turkish newborn fetuses

\section{MATERIAL and METHOD}

For this study, 40 lower limbs, right and left side, were utilized, from 20 Turkish newborn fetuses' (13 male and 7 female) $10 \%$ formalin-fixed cadavers. The skin was removed from the knee to the interdigital spaces. The lateral and anterior muscle compartments were opened in the leg, next to the intermuscular septum. The SPN was intently dissected, in a proximal to distal aspect, to its terminal branches in the distal forefoot. The course of the nerve and its branches were then traced where they perforated the crural fascia. The distance between the lateral malleolus and the site that the SPN left the fascia was measured. These courses were analyzed according to Adkinson's description (1).

On the dorsal surface of the foot, the lateral dorsal cutaneous nerve (LDCn) and SPN branches were identified. All branch divisions were dissected down to the interdigital space and their anatomical distributions were recorded. The distribution of branch divisions of the SPN, MDCn and IDCn were analyzed, which required dissection of the LDCn. The anatomical type, the direction, and the site of the communicating branch were noted in the malleolar tarsal and metatarsal regions with respect to the crest of the lateral malleolus and the base of the 5th metatarsal. The collateral branches coming from the communicating branch were counted and classified according to Kosinski's description from Canovas et al. (1996). The specimens were photographed with a digital camera (Power Shot A400, 3.2 Megapixel, Canon, China).

\section{RESULTS}

The course of SPN on the anterolateral part of the leg has been grouped into three types. In Type 1, observed in $75 \%$ of the cases (15 right - 15 left, 30 legs), the SPN lay on the anterolateral part of the leg over the lateral muscle compartment (Figure 1). In Type 2, observed in 15\% of the cases (3 right - 3 left, 6 legs), the SPN lay on the anterolateral part of the leg in the anterior muscle compartment (Figure 2). In Type 3, observed in $10 \%$ of the cases ( 2 right -2 left, 4 legs), the SPN divided in two parts on the anterolateral part of the leg and one of these

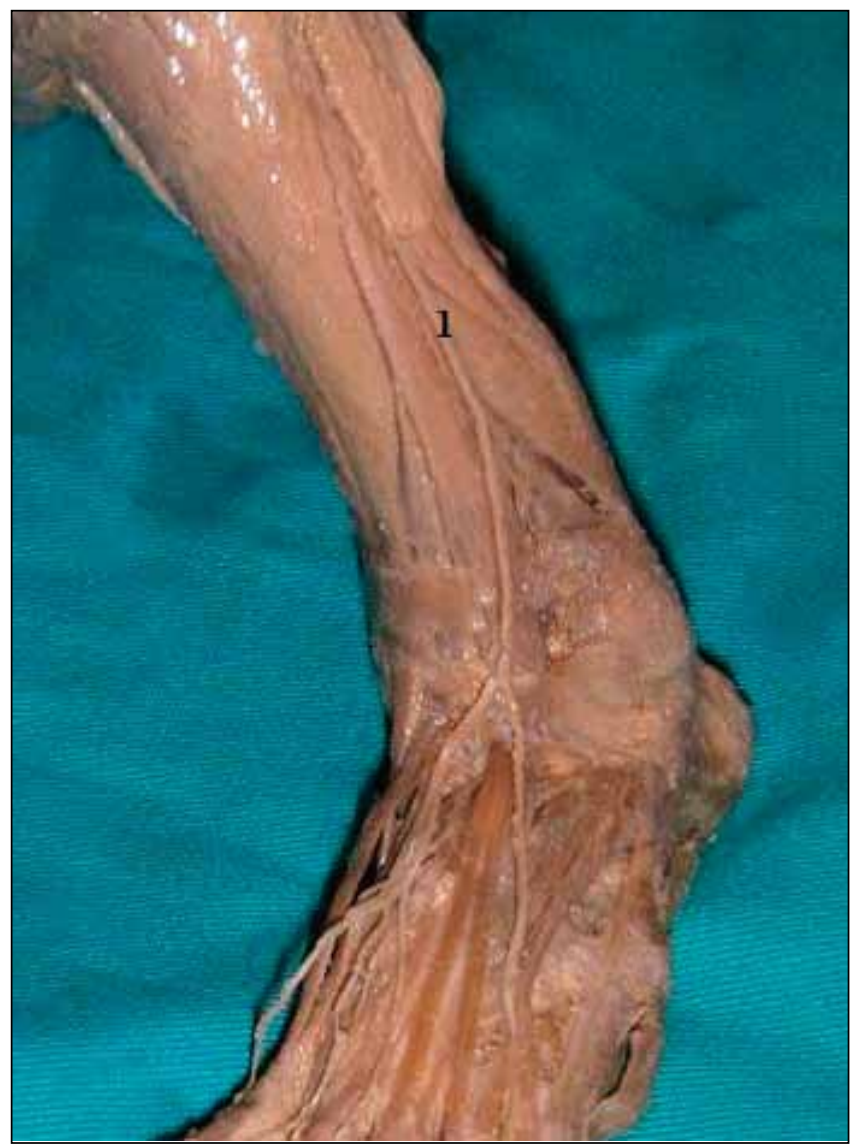

Figure 1: Course of the SPN within the lateral compartment: 1. Superficial peroneal nerve.

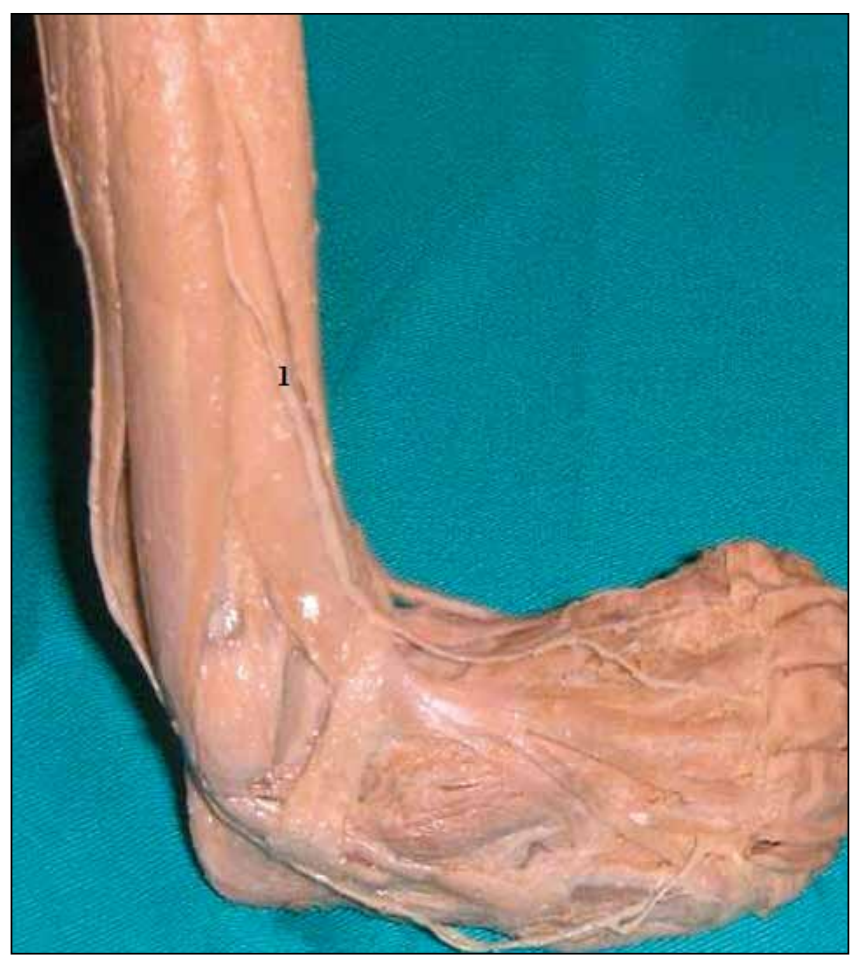

Figure 2: Course of the SPN within the anterior compartment: 1. Superficial peroneal nerve. 
branches laid on the lateral muscle compartment while the other laid on the anterior muscle compartment (Figure 3). The average distance between the lateral malleolus and the site that the SPN left the fascia was $18.8 \pm 3.47 \mathrm{~mm}$. There was no statistically significant difference between the right and left leg in the course of the SPN $(P<0.05)$.

The terminal branches of the SPN examined on the dorsal surface of the foot were of three types. In Type 1, the SPN divided into branches, the MDCn and the IDCn. The MDCn, which has three branches altogether, was observed to extend medially to the 1 st toe, whereas the middle branch extended to the middle of the 1 st and 2 nd toes and also made an anastomosis with deep peroneal nerve (DPN). The lateral branch was observed to extend laterally to the 2 nd toe and medially to the 3rd toe following another branching into two. On the other hand, the IDCn was first seen to divide into two branches on the dorsal side of the foot, and then produce two more branches to the side facing of the 3rd to 4th toes and 4th to 5th toes, at about the metatarsophalangeal joint. This type was observed in $82.5 \%$ of the samples (16 right - 17 left, 33 feet) (Figure 4). In Type 3, the SPN divided into branches, namely the MDCn and IDCn. The MDCn, which had three branches altogether, was observed to extend medially to the

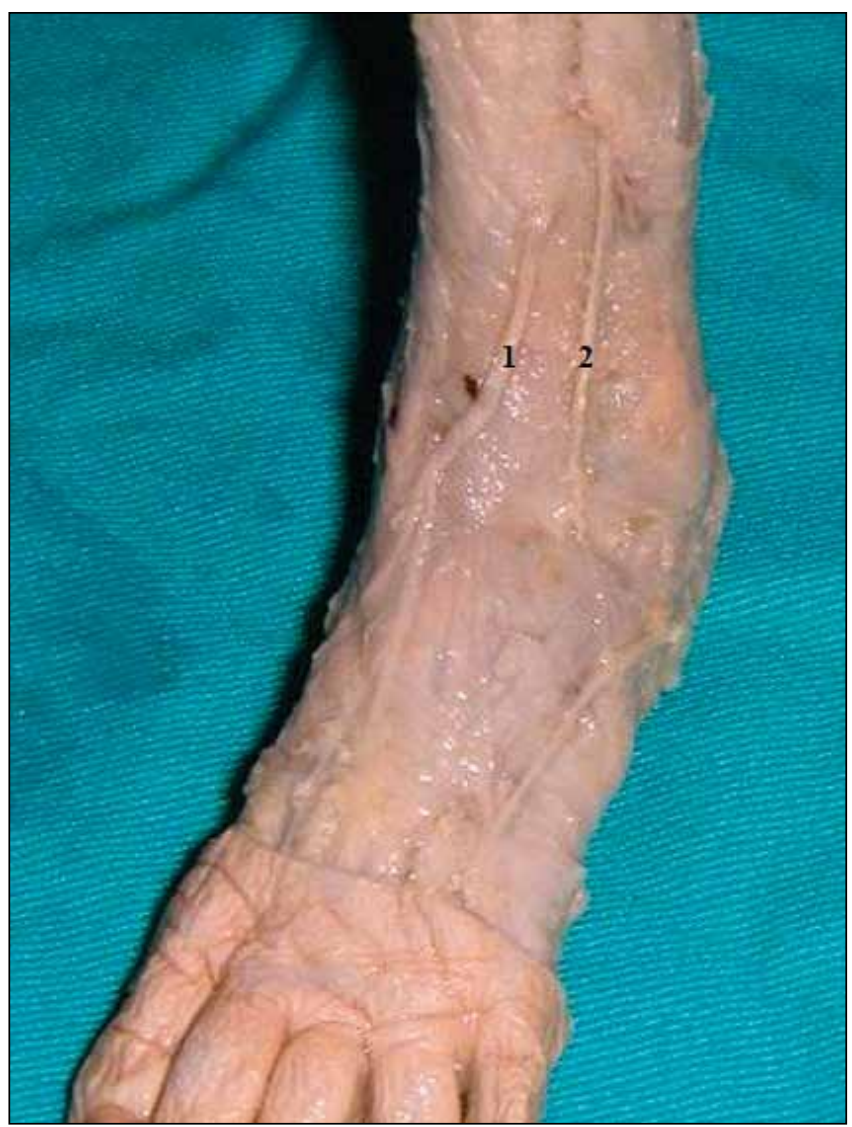

Figure 3: Course of the SPN within the lateral and anterior compartment: 1 . Medial dorsal cutaneous nerve, 2 . Intermediate dorsal cutaneous nerve. 1st toe, whereas the middle branch extended to the middle of the $1 \mathrm{st}$ and 2 nd toes and made an anastomosis with DPN.

The lateral branch was observed to extend laterally to the 2nd toe and medially to the 3rd toe, following another branching into two. On the other hand, the IDCn was observed to extend as one branch on the dorsal side of the foot, followed by branching into two immediately after the metatarsophalangeal joint and extending to the lateral side of the $3 \mathrm{rd}$ toe and the medial side of the 4 th toe. This type was observed in $10 \%$ of the samples (2 right - 2 left, 4 feet) (Figure 5). In Type 6, the SPN divided into the MDCn and IDCn. The MDCn, which had three branches altogether, was observed to extend medially to the 1st toe, whereas the middle branch extended to the middle of the 1 st and 2 nd toes and made an anastomosis with DPN. The lateral branch was observed to extend laterally to the 2nd toe and medially to the 3rd toe, following another branching into two.

On the other hand, IDCn divided into two branches on the dorsal side of the foot, and then produced two more branches to the side facing the $3 \mathrm{rd}$ to 4 th toes and 4 th to 5 th toes, at about the metatarsophalangeal joint. In addition, there was an anastomosis between the LDCn and IDCn. This type was seen in $7.5 \%$ of the samples (2 right- 1 left, 3 feet) (Figure 6). There was no statistically significant difference between right and left foot in the course of the SPN on the dorsal surface of the foot $(P<0.05)$.

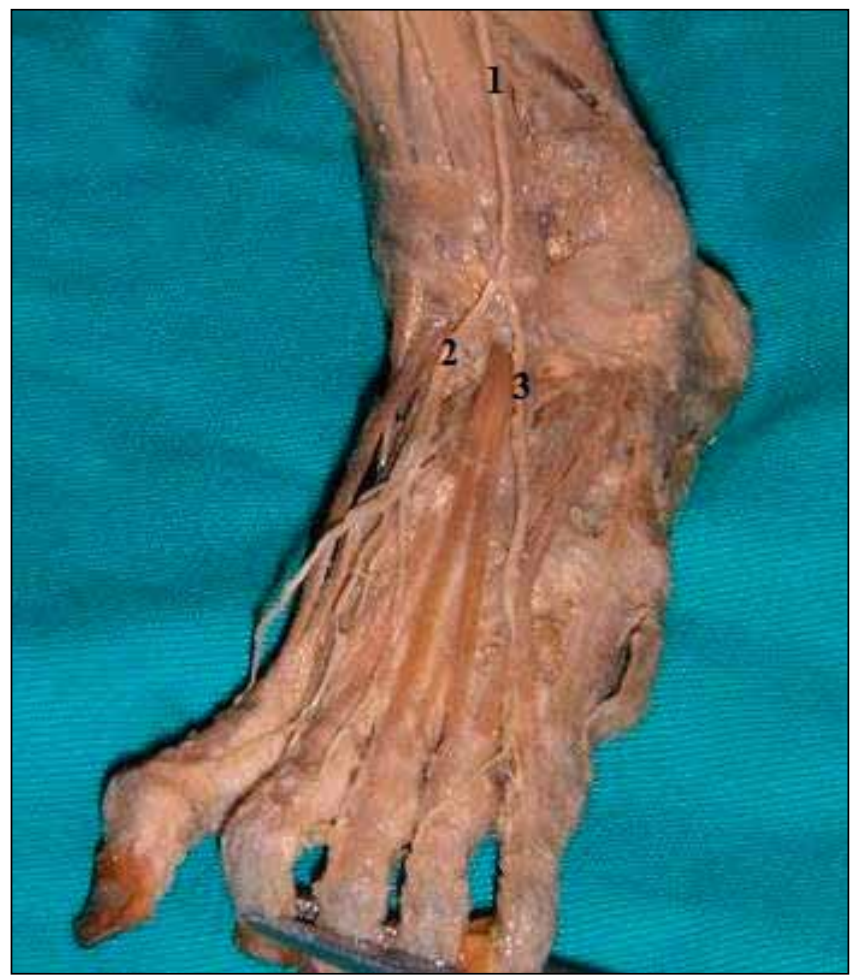

Figure 4: The course of terminal branches of SPN, According to Kosinski's classification type1: 1. Superficial peroneal nerve, 2. Medial dorsal cutaneous nerve, 3 . Intermediate dorsal cutaneous nerve. 


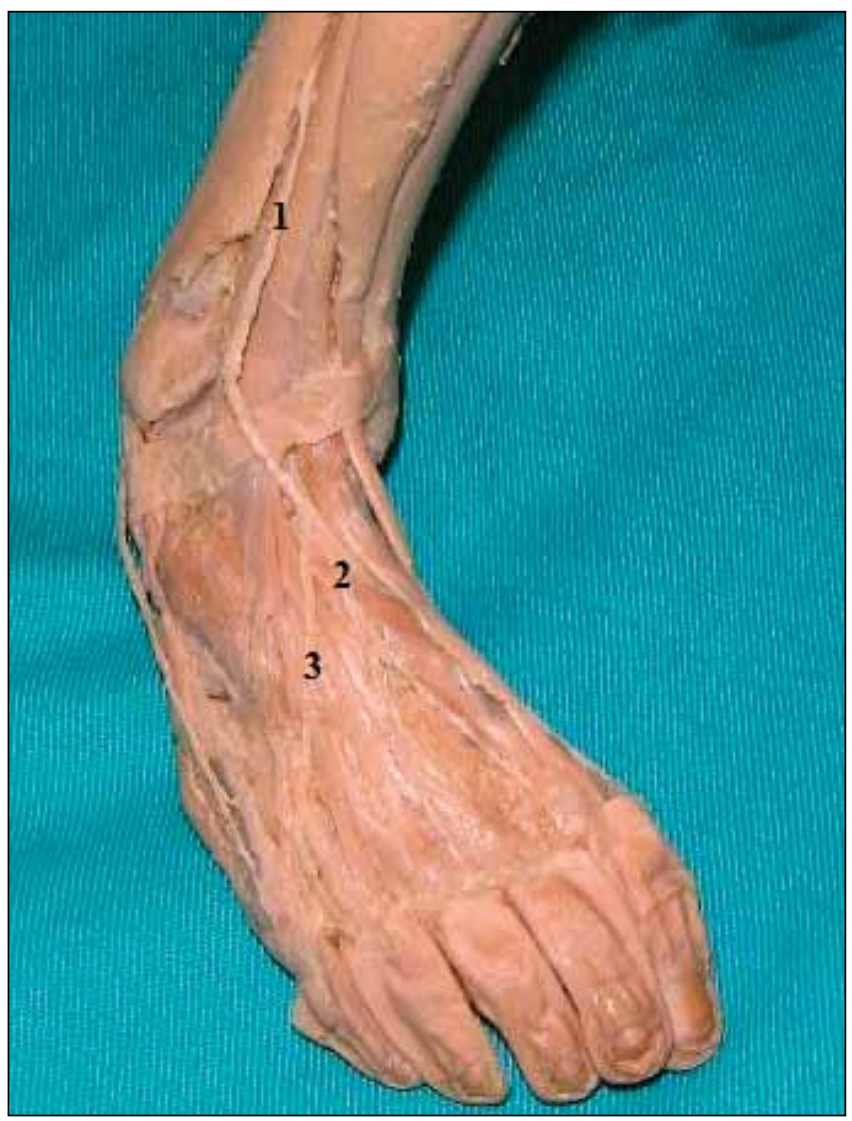

Figure 5: The course of terminal branches of SPN, According to Kosinski's classification type 3: 1 . Superficial peroneal nerve, 2. Medial dorsal cutaneous nerve,3. Intermediate dorsal cutaneous nerve.

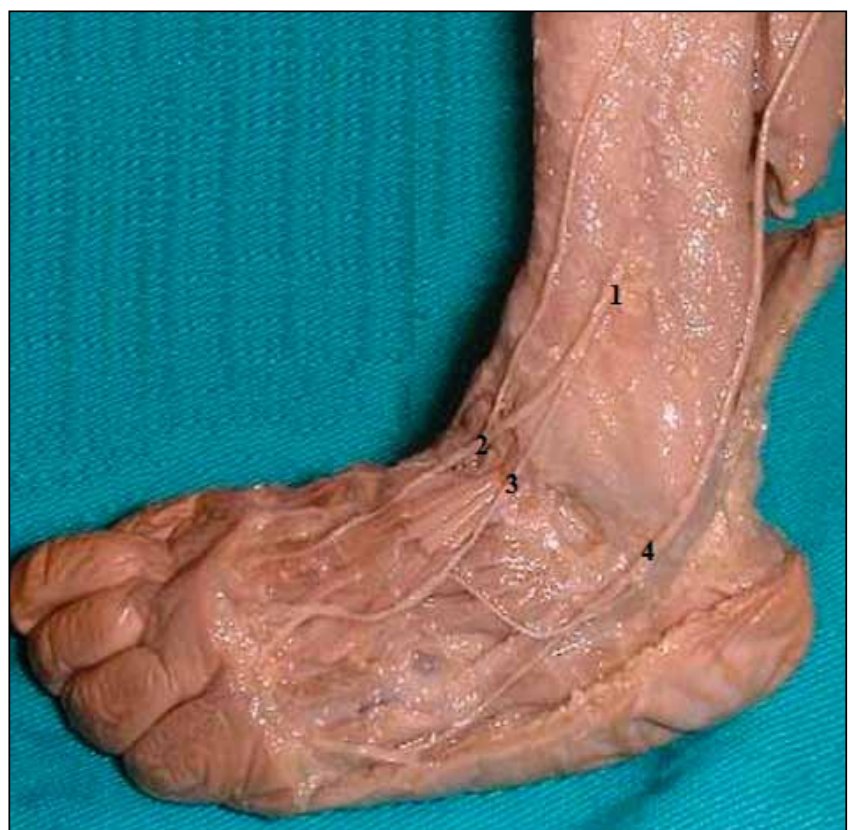

Figure 6: According to Kosinski's classification type 6: 1. Superficial peroneal nerve, 2. Medial dorsal cutaneous nerve, 3. Intermediate dorsal cutaneous nerve, 4. Lateral dorsal cutaneous nerve.

\section{STATISTICAL ANALYSIS}

Statistical analyses were carried out for the determination of variations of the SPN between right and left side of newborn cadavers. For this purpose, a Chi-square test was performed. Results were expressed as Mean \pm SEM. A P value less than 0.05 was considered statistically significant. Statistical analyses were performed using the SPSS (V. 10.0) software.

\section{DISCUSSION}

The SPN on the anterolateral surface of the leg and its terminal branches on the dorsal surface of the foot follow a highly variable anatomical course (6). The SPN is supecifically prone to injury and damage, such that if the nerve is stretched, damaged, or transected, the patient is at risk for losing sensation, muscle function, or developing a painful neuroma. Many types of surgeries are performed in the region of the mid-third of the lateral leg, including fasciotomy, arthroscopy, and nerve decompressions (11), putting the SPN in jeopardy. So, a good knowledge of the anatomical relationships and common variations of the superficial peroneal nerve is required to prevent injuries during surgical procedures $(16,17)$. A few studies on human fetuses (9) describe the course and branching pattern of SPN in the leg and foot.

The course of the SPN on the anterolateral surface on the leg was studied by Adkinson et al. in 85 legs of 44 cadavers, and the SPN was classified into four types. In their study, Type 1 was seen in which the nerve coursed within the lateral compartment in 62 samples, corresponding to about $73 \%$ of the cases. In twelve samples, about $14 \%$, Type 2 was seen in which the nerve had a variable course in the lateral compartment, then crossed into the anterior and passed through the crural fascia from the anterior muscle compartment. In ten samples, about $12 \%$, Type 3 was seen in which the nerve divided proximally, with two branches running separately in the lateral and the anterior compartments. In one sample, about 1\%, Type 4 was seen in which the nerve lay deep to the peroneus longus but ran along the deep surface of the fascia before exiting distally (1).

Ducic et al. reported their results of dissections of 111 legs to define the anatomical position of the SPN and found that the nerve had four distinct variations in location. In 77 (69.4\%) specimens, the nerve coursed within the lateral compartment of the leg, while in $18(16.2 \%)$ of the specimens, the nerve split and contained branches in both the lateral and anterior compartments. The nerve in seven (6.3\%) specimens was found within the intermuscular septum, and in nine $(8.1 \%)$ of the specimens, the SPN traveled only within the anterior compartment. Barrett et al. stated that, in the 75 specimens dissected, the SPN was found to be in the lateral compartment of the leg adjacent to the intermuscular septum in $72 \%$ of the specimens, in the anterior compartment in $23 \%$ of the specimens, and in both the anterior and the lateral compartments in $5 \%$ of the specimens. In a series of 38 cadaveric legs, Apaydin et al identified the SPN course in 27 cases $(71.0 \%)$ entirely in the lateral compartment, in 9 cases 
(23.7\%) the SPN passed through the anterior intermuscular septum from the lateral compartment and in 2 cases $(5.3 \%)$ the SPN coursed in both the lateral and the anterior compartments (3).

Our findings in the newborn cadavers can be classified into three groups; such that $75 \%$ of the samples belong to Type 1 with the nerve coursing within the lateral compartment of the leg, $15 \%$ are Type 2 with the nerve coursing within the anterior compartment of the leg and $10 \%$ were Type 3 with the nerve divided in two parts, with one branch laid on the lateral compartment and the other on the anterior compartment. On analyzing the research on this theme, our findings were verified. In the current work, we report for the first time that the average distance between the lateral malleolus and the site of the SPN left the fascia as $18.48 \pm 3.47 \mathrm{~mm}$ in the newborn cadavers. The variations in cutaneous innervations of the dorsum of foot are very important for avoiding iatrogenic injuries during various surgical procedures. The risks of iatrogenic injury to the MDCn and IDCn have been mentioned during operative procedures directed at the distal part of the fibula and the ankle (12).

On analyzing origin and termination of the branches, the SPN appeared to be quite variable. According to Kosinski's classification from Canovas, which describes 12 distributions, we found that our samples fall into three groups; $82.5 \%$ are Kosinski Type1, 10\% are Kosinski Type 3 and $7.5 \%$ are Kosinski Type 6. Canovas and Bonnel reported their results of dissections of the SPN of 30 adult cadavers and stressed the anatomical variations. Their results were reported as $80 \%$ Kosinski Type I and 20\% Kosinski Type II and III. Wahee et al. were carried out on 60 lower limbs of 19 male and 11 female fetuses ranging between 24 and 36 weeks of gestation. Their results were divided into six groups, 5\% Type $1 \mathrm{c}$ and $3 \%$ Type $3 \mathrm{~b}$ which corresponded to K1 and K3 in Kosinski's classification (20). Based on their work on 30 adult cadavers, Aktan and Ucerler reported that the variation in the distribution of the cutaneous nerve of the dorsum of the foot could be classified into seven types. In this study, the most common variant was $26.7 \%$ Type1, which corresponded to $1.7 \% \mathrm{~K} 4$ and $2.6 \%$ $\mathrm{K} 6$ in Kosinski's classification. The most frequent variants of Kosinski 55.4\% K5, K7, K8, K10, K11 and K12 were not seen in their study (2).

Solomon et al. described 11 nerve distribution types on the dorsum of the foot in 68 adults, but they ignored the various patterns of the communicating branches (18). Therefore, we classified our study according to Kosinski's descriptions. According to Hortwitz, the division of the SPN into its two branches was usually $6.4 \mathrm{~cm}$ above the external malleolus. The MDCn supplies the medial part of the dorsum of the foot, dividing into two branches, one to the medial side of the big toe and the other to adjacent sides of the second and third toes. The IDCn division supplies the intermediate portion of the dorsum of the foot, dividing into two branches. One supplies the adjacent surfaces of the third and fourth toes; the other terminates in the fourth and fifth toes and anastomoses with the sural nerve. This course resembles Kosinski Type 6 classification. The results suggest that the terminal branches of the SPN have great variations dorsally on the foot and, in total; it was found that the most frequent type was of the Kosinski Type 1 description. This standard distribution of the SPN branches is also described in certain anatomy textbooks. The course of SPN on the anterolateral surface on the leg and its terminal branches on the foot did not demonstrate statistical differences between right and left lower extremity in our study and there is no information about left and right lower extremity differences in the literature.

\section{CONCLUSION}

In this study, we showed the variations of SPN and its terminal branches on the leg and foot in the Turkish newborn fetuses. These variations are similar to those reported in the adult and there were no statistical differences between the left and right lower extremity. Anatomical variations of the SPN do not allow for the description of surgical approaches without risk of nerve injury. Detailed information about the SPN and its branches in early ages will be beneficial, particularly in planning surgeries.

\section{REFERENCES}

1. Adkinson DP, Bosse MJ, Gaccione DR, Gabriel KR: Anatomical variations in the course of the superficial peroneal nerve. J Bone Joint Surg Am 73(1): 112-114, 1991

2. Aktan Ikiz ZA, Ucerler $\mathrm{H}$ : The distribution of the superficial peroneal nerve on the dorsum of the foot and its clinical importance in flap surgery. Foot Ankle Int 27(6): 438-44, 2006

3. Apaydin N, Basarir K, Loukas M, Tubbs RS, Uz A, Kinik H: Compartmental anatomy of the superficial fibular nerve with an emphasis on fascial release operations of the leg. Surg Radiol Anat 30(1): 47-52, 2007

4. Arinci K, Elhan A: Anatomi II. Ankara: 1997, 232-233

5. Barrett SL, Dellon AL, Rosson GD, Walters L: Superficial peroneal nerve (Superficial Fibularis Nerve): The clinical implications of anatomic variability. J Foot Ankle Surg 45(3): 174-176, 2006

6. Blair JM and Botte MJ: Surgical anatomy of the superficial peroneal nerve in the ankle and foot. Clin Orthop 305: 229-238, 1994

7. Browne JA, Morris MJ: Variant superficial fibular (peroneal) nerve anatomy in the middle third of the lateral leg. Clin Anat 20: 996-997, 2007

8. Canovas F, Bonnel F, Kouloumdjian P:The superficial peroneal nerve at the foot, organisation, surgical applications. Surg Radiol Anat 18: 241-244, 1996

9. Domagala Z, Gworys B, Porwolik K: Preliminary assessment of anatomical variability of nervus peroneus superficialis in the foetal period. Folia Morphol 62(4): 401-403, 2003

10. Drizenko A, Demondion X, Luyckx F, Mestdagh $H$, Cassagnaud $X$ : The communicating branches between the sural and superficial peroneal nerves in the foot: A review of 55 cases. Surgical and Radiologic Anatomy 26(6): 447-452, 2004 
11. Ducic I, Dellon AL, Graw KS: The clinical importance of variations in the surgical anatomy of the superficial peroneal nerve in the mid-third of the lateral leg. Ann Plast Surg 56(6): 635-638, 2006

12. Heune DB, Bunnel WP: Operative anatomy of nerves encountered in the lateral approach to the distal part of fibula. J Bone Joint Surg 77: 1021-1024, 1995

13. Hortwitz MT: Normal anatomy and variations of the peripheral nerves of the leg and foot. Arch Surg 36: 626-636, 1938

14. Kim DH, Kline DG: Management and results of peroneal nerve lesions. Neurosurgery 39: 312-320, 1996

15. McGreor-Riley JC, Farhan MJ: Entrapment of the terminal branches of the superficial peroneal nerve on the dorsum of foot. Report of two unusual cases and review of the literature. The Foot 12: 21-26, 2002

16. Nagabhooshana S, Vollala VR, Rodrigues V, Rao M: Anomalous superficial peroneal nerve and variant cutaneous innervation of the sural nerve on the dorsum of the foot: A case report. Cases J 18(2):197, 2009
17. Pacha D, Carrera A, Llusa M, Permanyer E, Molona O, Morro R: Clinical anatomy of the superficial peroneal nerve in the distal leg. Eur J Anat 1: 15-20, 2003

18. Solomon LB, Ferris L, Tedman R, Henneberg M: Surgical anatomy of the sural and superficial fibular nerves with an emphasis on the approach to the lateral malleolus. J Anat 199: 717-723, 2001

19. Tank PW: Grant's Dissector. 13 (ed). Philadelphia: Lippincott Williams \& Wilkins, 2005:138

20. Wahee P, Aggarwal A, Harjeet, Sahni D: Variable patterns of cutaneous innervation on the dorsum of foot in fetuses. Surg Radiol Anat 32(5): 469-475, 2010

21. Williams EH, Dellon AL: Intraseptal superficial peroneal nerve. Microsurgery 27:477-480, 2007

22. Yang LJ, Gala VC, McGillicuddy JE: Superficial peroneal nerve syndrome: An unusual nerve entrapment case report. J Neurosurg 104(5): 820-823, 2006 